Article

\title{
Enhanced Photophysical Properties of Nanopatterned Titania Nanodots/Nanowires upon Hybridization with Silica via Block Copolymer Templated Sol-Gel Process
}

\author{
Dinakaran Kannaiyan ${ }^{1, \dagger}$, Saji Thomas Kochuveedu ${ }^{1, \dagger}$, Yoon Hee Jang ${ }^{1}$, Yu Jin Jang ${ }^{1}$, \\ Ji Yong Lee ${ }^{1}$, Jieun Lee ${ }^{1}$, Juyon Lee ${ }^{1}$, Jooyong Kim ${ }^{2}$ and Dong Ha Kim ${ }^{1}{ }^{\text {** }}$
}

1 Department of Chemistry and Nano Science, Division of Molecular and Life Sciences, College of Natural Sciences, Ewha Womans University, 11-1 Daehyun-dong, Seodaemun-gu, Seoul 120-750, Korea; E-Mails: dinakark@yahoo.com (D.K.); stkochuveedu@gmail.com (S.T.K.); 1985hee@hanmail.net (Y.H.J.); breezeyam@gmail.com (Y.J.J.); shinjo7@hanmail.net (J.Y.L.); jieun0122@gmail.com (J.L.); ashez@naver.com (J.L.)

2 Department of Organic Materials and Fiber Engineering, Soongsil University, 511 Sangdo-Dong, Dongjak-Gu, Seoul 156-743, Korea; E-Mail: jykim@ssu.ac.kr (J.K.)

* Author to whom correspondence should be addressed; E-Mail: dhkim@ewha.ac.kr;

Tel.: +82-2-3277-4124; Fax: +82-2-3277-3419.

$\dagger$ The authors contributed equally to this work.

Received: 28 September 2010; in revised form: 18 October 2010 / Accepted: 21 October 2010 / Published: 25 October 2010

\begin{abstract}
We fabricated titanium dioxide $\left(\mathrm{TiO}_{2}\right)$-silica $\left(\mathrm{SiO}_{2}\right)$ nanocomposite structures with controlled morphology by a simple synthetic approach using cooperative sol-gel chemistry and block copolymer (BCP) self-assembly. Mixed $\mathrm{TiO}_{2}-\mathrm{SiO}_{2}$ sol-gel precursors were blended with amphiphilic poly(styrene-block-ethylene oxide) (PS-b-PEO) BCPs where the precursors were selectively incorporated into the hydrophilic PEO domains. Changing the volumetric ratio of $\mathrm{TiO}_{2}-\mathrm{SiO}_{2}$ sol-gel precursor from $5 \%$ to $20 \%$, a stepwise structural inversion occurred from nanodot arrays to discrete nanowires. Template free hybrid inorganic nanostructures were produced after the removal of PS-b-PEO by irradiation of UV light. The morphological evolution and photophysical properties were investigated by microscopic studies, UV-visible absorption and photocatalytic properties.
\end{abstract}


Keywords: hybrid $\mathrm{TiO}_{2}-\mathrm{SiO}_{2}$; poly(styrene-block-ethyleneoxide); sol-gel; nanopattern; photocatalyst

\section{Introduction}

Titanium dioxide $\left(\mathrm{TiO}_{2}\right)$ based nano materials has gained considerable attention due to its unique physicochemical properties, such as non-toxicity, insolubility, stability and high photoactivity, based on which widespread applications were accomplished [1-4]. Numerous routes to synthesize low dimensional $\mathrm{TiO}_{2}$ in a controlled condition have been reported [5-7]. These are particularly useful in the field of environmental remedy due to active photocatalytic properties [8-10]. Since one of the important criteria for effective photosensitization is to adsorb the dye on the $\mathrm{TiO}_{2}$ surface followed by the photodegradation under light irradiation on the $\mathrm{TiO}_{2}$ surface, large surface area and high adsorption capacity are the prime prerequisites in order to enhance photoactivity of $\mathrm{TiO}_{2}$. $\mathrm{Among}$ established protocols to improve the efficiency of nanostructured $\mathrm{TiO}_{2}$ as photocatalysts, it was reported that dispersion in a nonreactive, photo inert, adsorbent material, such as silicas, can be an effective method, where the physico-chemical properties of hybrid silica/titania are distinctly different from those of the single component counterparts; thus demonstrating great promise for a range of potential applications [11-14]. In this context, hybrid silica-titania nanostructures have emerged as one of the typical alternative systems that may replace neat $\mathrm{TiO}_{2}$ analogues.

Composite inorganic nanostructures in one-dimensional structures constitute a novel class of functional material that has attracted significant interest due to their potential applications in the development of innovative smart devices and systems. One of the key requirements to produce $\mathrm{TiO}_{2}$ based nano-devices is the feasibility to integrate 1D addressable nanostructure through assembly, patterning, and alignment on technologically relevant solid supports [15-17]. Among the strategies of simpler, cost-effective means to attain this goal, self-assembly has been recognized as one of the most effective pathways toward controlled organization of functional nanomaterials $[18,19]$.

Block copolymers (BCPs) represent a typical example of self-assembly systems that organize into various periodic nanostructures owing to their microphase separation between dissimilar blocks. The morphology of the BCP self-assembled pattern is determined by the volume fraction of the components and the strength of the segmental interaction between the blocks [20-22]. Of the versatile aspects of BCPs, fabrication of organic-inorganic nanocomposite structures using BCPs as structure directing agents is a well known application. For instance, inorganic sol-gel precursors [23-27] and inorganic nanoparticles [28,29] can be incorporated into one of the constituent blocks having a similar polarity to generate an inorganic nanostructure that is essentially the replica or modulated nanostructure of the initial BCP [30-32]. Silica/BCP films with various mesostructures of large characteristic length scales were synthesized through evaporation-induced self-assembly, where amphiphilic polystyrene-block-poly(ethyleneoxide) (PS-b-PEO) diblock copolymer and triblock copolymer (P123) were used as the structure-directing agents [33]. We recently reported that $\mathrm{TiO}_{2}$ nanostructures with tailored morphology could be prepared by one-step spin coating a common solution composed of PS- $b$-PEO and sol-gel precursors with controlled 
composition, and compared their photocatalytic efficiency [31,34]. However, none of the previous studies on $\mathrm{TiO}_{2}$ nanostructures based on the combination of BCP and sol-gel chemistry explored their hybridization with $\mathrm{SiO}_{2}$ for the modification of $\mathrm{TiO}_{2}$ properties. Here, we further develop our previous methodology to produce highly dense arrays of $\mathrm{TiO}_{2} / \mathrm{SiO}_{2}$ nanocompsite structures in a mixed $0 \mathrm{D} / 1 \mathrm{D}$ configuration on a substrate, and investigate their morphological evolution as a function of the composition and their modified photocatalytic performance.

\section{Results and Discussion}

\subsection{Scheme}

The schematic representation of the experimental procedure to fabricate arrays of $\mathrm{SiO}_{2}-\mathrm{TiO}_{2}$ composite nanodots/nanowires is depicted in Scheme 1. Common solutions containing PS- $b$-PEO and sol-gel precursors were prepared first. To this end, TEOS and TTIP were dissolved in IPA together with $\mathrm{HCl}$ as catalyst, which was then added to the polymer solution. In a typical experiment, $1 \mathrm{wt} \%$ solution of PS- $b$-PEO in 1,4-dioxane was mixed with the desired amount of sol-gel precursor solution, where the inorganic precursors are selectively incorporated into the PEO domains due to coordinate interaction. Spin coating the organic-inorganic solution on silicon substrates produces composite thin films. Here the self-assembly of diblock copolymer driven by microphase separation and the relative ratio of PS- $b$-PEO to sol-gel precursors dictates the morphology of hybrid films. Arrays of pure $\mathrm{SiO}_{2}-\mathrm{TiO}_{2}$ composite dots/wires were obtained after removal of the BCP template by UV exposure in air for 24 hours. The yellow and blue regions represent PS domains and composite PEO-inorganic ones, respectively.

Scheme 1. Schematic diagram to generate self-assembled hybrid nanowire arrays of $\mathrm{SiO}_{2}-\mathrm{TiO}_{2}$ in PS- $b$-PEO thin films. $1 \mathrm{wt} \%$ PS- $b$-PEO in dioxane was mixed with $\mathrm{SiO}_{2} / \mathrm{TiO}_{2}$ sol-gel precursors. The common solution was spin cast on quartz or silicon substrates for photocatalytic and morphological studies, respectively.

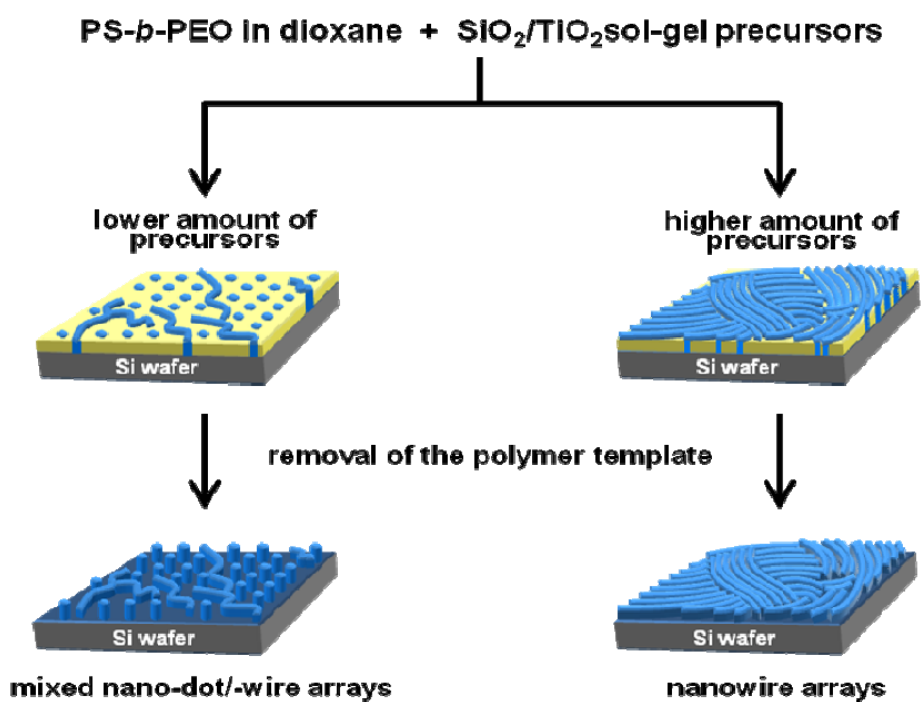




\subsection{Chemical Structure}

The possible mechanism for the formation of the $\mathrm{TiO}_{2}-\mathrm{SiO}_{2}$ composite semiconductor oxides can be attributed to the strong interaction between titania and silica particles at a molecular level and the chemical bond at the interface through Ti-O-Si bonds as evidenced from the IR spectrum (discussed in section 2.5). TTIP is partially hydrolyzed in the presence of acid to form loosely crosslinked gel, which then form polytitanosiloxane with TEOS. The replacement of alkyl groups of $\mathrm{TiO}_{2}$ precursors by $\mathrm{OH}$ groups during hydrolysis of TTIP leads to the interaction between $\mathrm{OH}$ groups and oxygen atoms of PEO blocks. Thereby, composite $\mathrm{TiO}_{2}-\mathrm{SiO}_{2}$ can be viably incorporated into the PEO blocks as depicted in Figure 1.

Figure 1. Proposed chemical structure of $\mathrm{PS}-b-\mathrm{PEO} / \mathrm{SiO}_{2} / \mathrm{TiO}_{2}$ composite.

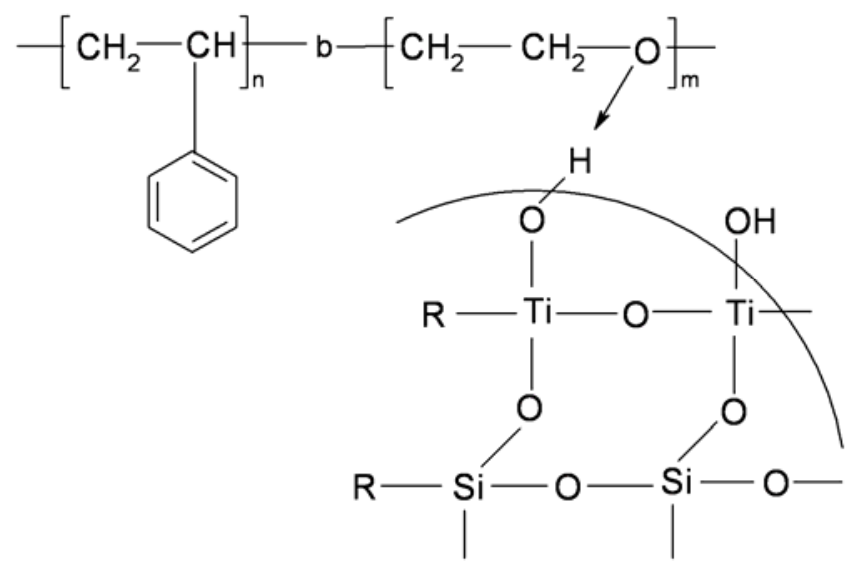

\subsection{Morphology Study}

We first investigated the morphological evolution of a series of PS- $b$-PEO thin films upon the addition of $\mathrm{SiO}_{2}-\mathrm{TiO}_{2}$ sol-gel precursor with different relative amounts using atomic force microscopy (AFM) images, as displayed in Figure 2 and supporting information Figure S1-S3. The relative amount of sol-gel precursor to the BCP solution were controlled in the range of $10 \sim 20 \%$ by volume with the Ti/Si mass ratio $0.5 \sim 1.5$. Figure 2 shows phase-contrast $\mathrm{AFM}$ images of $\mathrm{BCP} / \mathrm{SiO}_{2}-\mathrm{TiO}_{2}$ composite thin films with the relative amount of sol-gel precursor to the BCP solution $(10 \%$ in Figure $2 \mathrm{~b}$ and $20 \%$ in Figure $2 \mathrm{~d}$ ) and the Ti/Si mass ratio fixed at 0.5 . In all the AFM images, PEO nanodomains, containing harder inorganic moieties, appear brighter than PS domains. It is observed that the formation of nanoscale surface feature is exclusively dependent on the relative amount of sol-gel precursor. If sol-gel precursors were included in the BCP film (Figure $2 b, 2 d$ ), the surface morphology is remarkably changed compared with the control film without sol-gel precursor (Figure 2a). Upon increasing the relative amount of sol-gel precursor to the BCP solution from $10 \mathrm{vol} \%$ to $20 \mathrm{vol} \%$, a dramatic transformation from nanodot to nanowire structures was observed, where the brighter areas are hybrid PEO domains infiltrated with $\mathrm{SiO}_{2}$ and $\mathrm{TiO}_{2} \mathrm{moieties}$ Prolonged UV exposure, which can be used to etch out the organic matrix [35,36], was used as a tool to obtain arrays of pure inorganic nanodot (Figure 2c) and nanowire (Figure 2e). 
Figure 2. Phase contrast AFM images of the surfaces of (a) neat PS- $b$-PEO film; (b) $\mathrm{PS}-b-\mathrm{PEO} / \mathrm{SiO}_{2}-\mathrm{TiO}_{2}$ film containing $10 \mathrm{vol} \%$ inorganic precursors; (c) identical film in (b) after removing the BCP templates; (d) $\mathrm{PS}-b-\mathrm{PEO} / \mathrm{SiO}_{2}-\mathrm{TiO}_{2}$ film containing $20 \mathrm{vol} \%$ inorganic precursors; (e) identical film in (d) after removing the BCP templates. The hybrid films were prepared from spin coating dioxane solutions. The Ti/Si mass ratio is 0.5 .
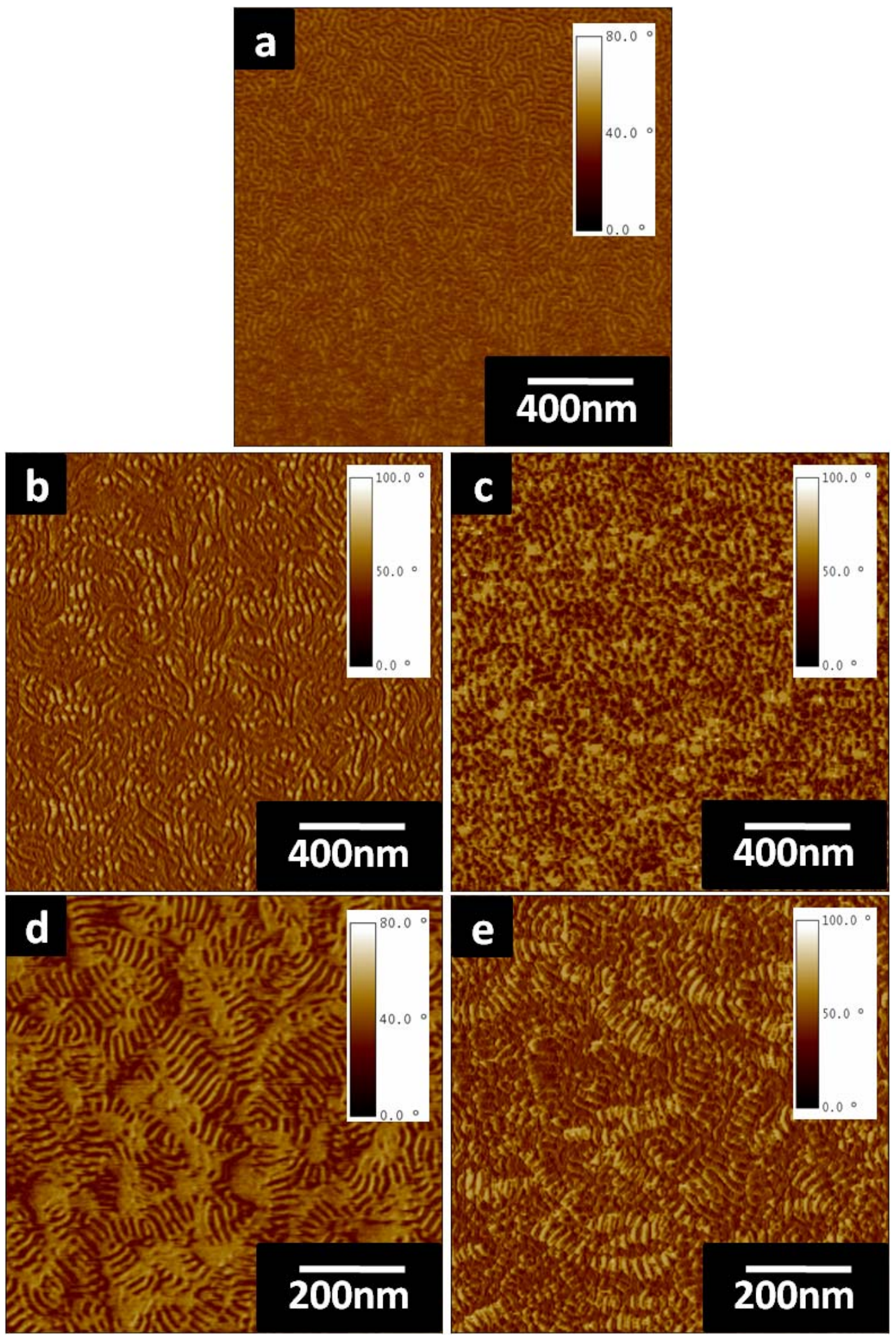
A similar trend of morphological conversion has been observed when a relatively high content of Ti $(\mathrm{Ti} / \mathrm{Si}$ mass ratio $=1.5)$ was introduced in the system. In typical film morphology, characteristic nanobelt structure was observed for the film with 20 vol\% of sol-gel precursor (see Figure S1 and S2 in the supporting information). However, neither titania or silica sol-gel precursor/BCP solution yield nanowire morphology in dioxane solvent system given the amount of sol-gel precursor. For comparison, the combined sol-gel alone produced nanowire morphology with BCP at the same amount of $\mathrm{HCl}$. The nanoscopic silica-titania particles are formed through hydrolysis and condensation of the TEOS and TTIP precursors. Upon mixing the precursors with the PS- $b$-PEO solution, they start to selectively swell the PEO block through specific interaction and evaporation of the volatile organic solvents. Scheme 1 schematically shows typical nanopatterned morphology that can be designed and obtained by a cooperative self-assembly of BCP and sol-gel precursors. The relative volume ratio between the PS and PEO block is a primary factor to define the morphology of the films. In addition, the relative amount of sol-gel precursors in common solutions is another critical parameter to direct the types of nanopatterns of the resulting hybrid thin films since the precursors selectively infiltrates and swell the hydrophilic PEO domains. Thus, a unique library of nano-textures including nanodot, nanowire, and a mixed intermediate one can be derived by this approach.

In order to produce nanodot arrays, a common solution composed of sol-gel precursors and the PS- $b$-PEO was prepared in toluene. Arrays of pure $\mathrm{SiO}_{2} / \mathrm{TiO}_{2}$ composite NPs are obtained after removal of the BCP template by UV etching as shown in the AFM phase contrast image in Figure 3. These results indicate that the selectivity of the solvent over the two antagonistic polymers dominantly dictates the formation of either nanodot or nanowire morphology.

Figure 3. Phase contrast AFM images of the surfaces of (a) $\mathrm{PS}-b-\mathrm{PEO} / \mathrm{SiO}_{2}-\mathrm{TiO}_{2}$ film containing $20 \mathrm{vol} \%$ inorganic precursors prepared from spin coating toluene solutions; (b) identical film in (a) after removing the BCP templates. The Ti/Si mass ratio is 1.0.
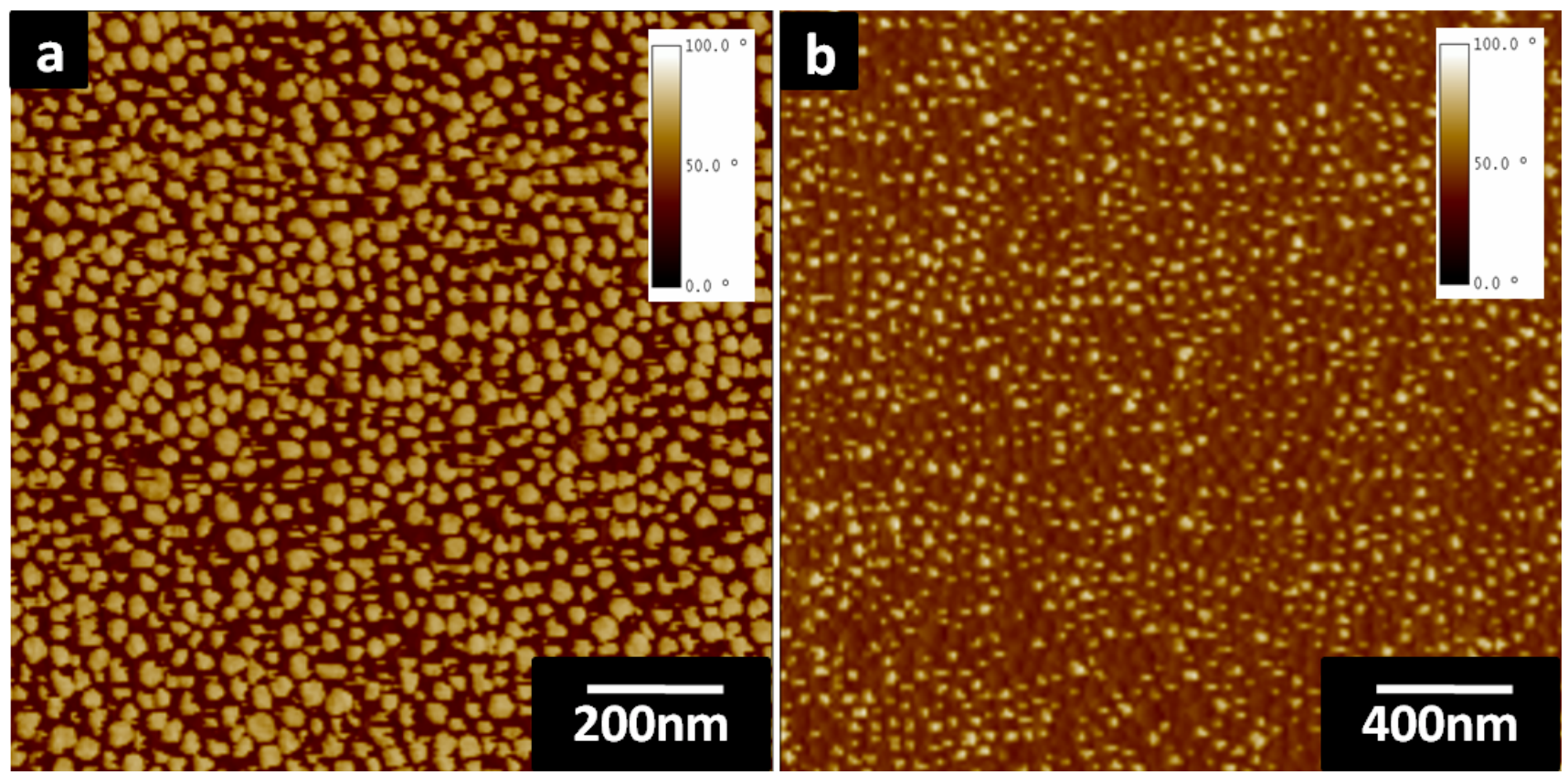


\subsection{UV-visible Absorption}

The UV-visible absorption spectra of $\mathrm{BCP} /$ silica-titania composite films are obtained in order to investigate the change in optical property via hybridization (Figure 4), where the mass ratio between $\mathrm{Si}$ and Ti varied from 0.5 to 1.5 , which is depicted as SEO-Si/Ti 0.5 to SEO-Si/Ti 1.5. The spectrum of the hybrid film shows characteristic absorption of $\mathrm{TiO}_{2}$ between 450 and $250 \mathrm{~nm}$. The UV absorption edge for the $\mathrm{Ti} / \mathrm{Si}$ (1.5) sample overlaps the overall spectrum of pure $\mathrm{TiO}_{2}$. The intensity of the UV absorption edge increases with increasing the content of Si in the mixed oxides appreciably.

Figure 4. UV-visible absorbance spectra of $\mathrm{PS}-b-\mathrm{PEO} / \mathrm{SiO}{ }_{2}-\mathrm{TiO}_{2}$ composite thin films containing $20 \mathrm{vol} \%$ sol-gel precursors with three different $\mathrm{Ti} / \mathrm{Si}$ mass ratios.

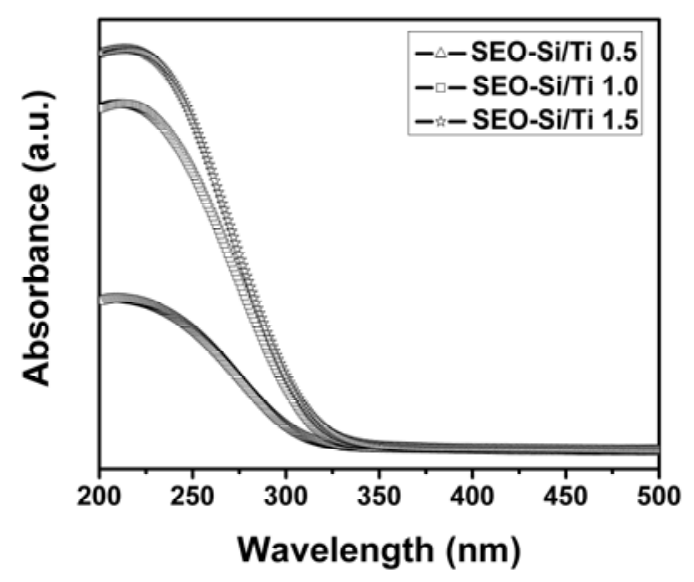

\subsection{FTIR Spectrum}

The FTIR spectra of $\mathrm{BCP} / \mathrm{SiO}_{2} / \mathrm{TiO}_{2}$ composite films containing $20 \mathrm{vol} \%$ sol-gel precursors with three different $\mathrm{Ti} / \mathrm{Si}$ mass ratios are presented in Figure 5 . The characteristic bands of Si-O-Si vibrations dominate in the IR spectra. The ones around $1060 \mathrm{~cm}^{-1}$ and $810 \mathrm{~cm}^{-1}$ are attributed to the asymmetric and symmetric Si-O-Si stretching modes, respectively. The peaks at 3348 and $1630 \mathrm{~cm}^{-1}$ are due to the stretching and bending vibration of $\mathrm{OH}$ groups. The band around $1387 \mathrm{~cm}^{-1}$ is assigned to the Ti-O-Ti stretching mode while the broad one in the $910-960 \mathrm{~cm}^{-1}$ region is related to the motion of Ti-O-Si bonds [11].

Figure 5. FTIR spectrum of a typical hybrid PS- $b-\mathrm{PEO} / \mathrm{SiO}_{2}-\mathrm{TiO}_{2}$ thin film with a ratio of $\mathrm{Ti} / \mathrm{Si}=1$.

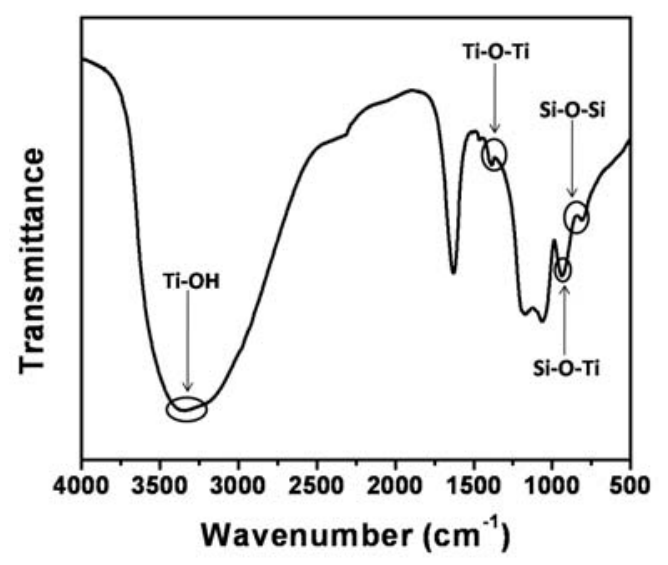




\subsection{Photocatalysis}

Finally, we explore the functional property of $\mathrm{SiO}_{2} / \mathrm{TiO}_{2}$ nanocomposite structures in terms of photocatalysis by referencing PS- $b-\mathrm{PEO} / \mathrm{TiO}_{2}$ films. The degradation of methylene blue (MB) under UV-vis light was performed; the results of which are displayed in Figure 6. The samples deposited on quartz substrates were immersed in a UV cuvette filled with $10 \mathrm{ppm}$ aqueous MB solution and kept in the dark for 1 hour to check the absorption of dye onto the catalyst surface followed by irradiation with UV light of $254 \mathrm{~nm}$ wavelength for a specified length of time. The ratio of the intensity of the absorbance peak at $664 \mathrm{~nm}$, before and after irradiation $\left(\mathrm{I} / \mathrm{I}_{0}\right)$ was correlated and displayed with time in Figure 6. It is found that the degradation efficiency of $\mathrm{BCP} / \mathrm{SiO}_{2}-\mathrm{TiO}_{2}$ thin film was higher than that of $\mathrm{BCP} / \mathrm{TiO}_{2}$ for same amount of $\mathrm{TiO}_{2}$ content.

Figure 6. Photocatalytic degradation of methylene blue: plot of the ratio of intensity of peak at $664 \mathrm{~nm}\left(\mathrm{I} / \mathrm{I}_{0}\right)$ with time.

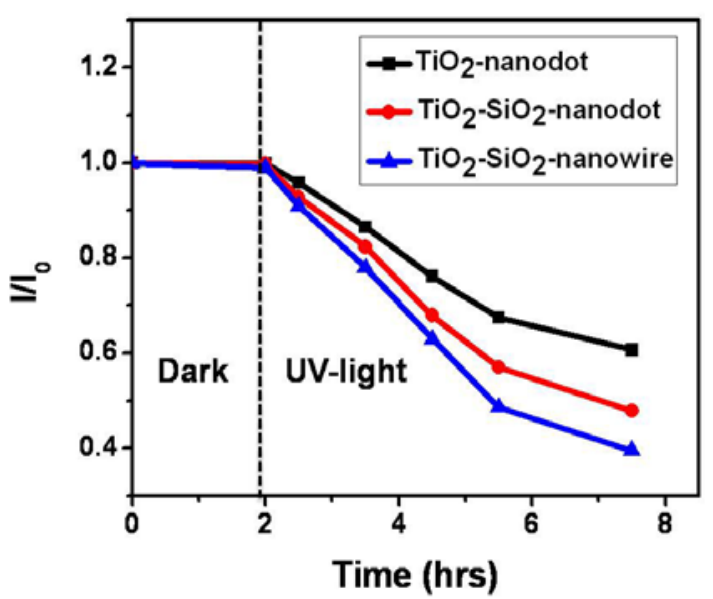

\subsection{Mechanism of the Enhancement of Photocatalytic Activity}

Upon excitation with UV light, pairs of electrons and holes are generated in $\mathrm{TiO}_{2}$ semiconductor. The photogenerated electrons then react with molecular oxygen $\left(\mathrm{O}_{2}\right)$ to produce superoxide radical anions $\left(\mathrm{O}_{2}{ }^{-}\right)$, and the holes react with water typically to produce hydroxyl radicals $(\mathrm{OH})$. These two types of reactive radicals can participate together in decomposing organic dyes as schematically illustrated in Figure 7. The enhanced photocatalytic activity can be attributed to the unique physicochemical properties of $\mathrm{TiO}_{2}-\mathrm{SiO}_{2}$ composite nanostructures resulting from a strong interaction between titania and silica moieties at molecular level, based on smaller crystallite size, improved surface roughness and the generation of new strong acid sites on the surface [37]. Since the photodegradation takes place only on the surface of photocatalytic $\mathrm{TiO}_{2}$ center, the presence of an adsorbent like $\mathrm{SiO}_{2}$ along with $\mathrm{TiO}_{2}$ augment to improve the concentration of dye in the vicinity of $\mathrm{TiO}_{2}$, which leads to the enhancement of the rate of degradation of dye (Figure 6) $[38,39]$. 
Figure 7. Electron transfer mechanism between dye and $\mathrm{TiO}_{2}$ with the role of $\mathrm{SiO}_{2}$.

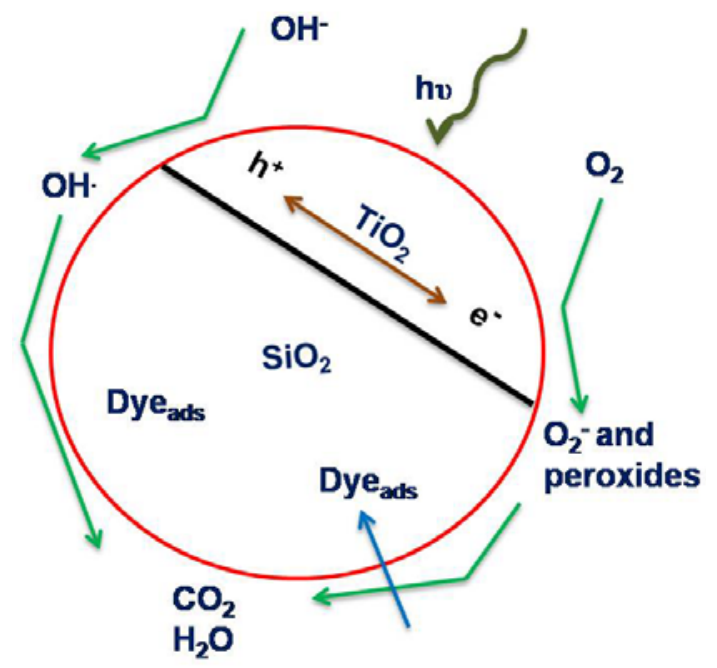

\section{Experimental Section}

\subsection{Materials}

Asymmetric poly(styrene-block-ethylene oxide) block copolymer (PS-b-PEO) with a polydispersity index of 1.05 was purchased from Polymer Source, Inc. The number average molecular weights of PS and PEO blocks are 20,000 $\mathrm{g} / \mathrm{mol}$ and $6,500 \mathrm{~g} / \mathrm{mol}$, respectively. Titanium tetra-isopropoxide (TTIP, 99.99\%, Sigma Aldrich Inc.), and tetraethyl orthosilicate (TEOS, 98\%, Sigma Aldrich Inc.) were purchased from Aldrich and used as received. Analytical grade toluene, isopropyl alcohol (IPA) and hydrochloric acid $(\mathrm{HCl})$ were purchased from Laborbedarf $\mathrm{GmbH}$.

\section{2. $\mathrm{TiO}_{2}$ Sol-gel Precursor Solution}

The sol-gel titania precursor solution was prepared by adding $\mathrm{HCl}(0.25 \mathrm{~g})$ into $5 \mathrm{~mL}$ IPA containing TTIP $(0.71 \mathrm{~g})$. The mixture was stirred for 24 hours.

\section{3. $\mathrm{SiO}_{2}-\mathrm{TiO}_{2}$ Sol-gel Precursor Synthesis}

$0.25 \mathrm{~g}$ of concentrated $\mathrm{HCl}(37 \%)$ was slowly added into $5 \mathrm{~mL}$ IPA containing $0.4 \mathrm{~g}$ of TTIP and $0.3 \mathrm{~g}$ of TEOS and stirred for more than 24 hours.

\subsection{Film Preparation}

The desired amount of sol-gel precursor solution was mixed with the $1 \mathrm{wt} \% \mathrm{PS}-b$-PEO in dioxane and stirred for 12 hours. Similarly the desired amount of sol-gel precursor was mixed with a $1 \mathrm{wt} \%$ solution of PS- $b$-PEO in toluene. The hybrid inorganic $\left(\mathrm{SiO}_{2}-\mathrm{TiO}_{2}\right)$-organic polymer films were produced simply by spin-coating the mixture solution on a piece of silicon substrate at 2,000 rpm for $60 \mathrm{sec}$. Thin films were obtained by spin coating common solutions consisting of PS- $b$-PEO and precursors on solid substrates at $2000 \mathrm{rpm}$ for $1 \mathrm{~min}$. The obtained films were dried under ambient 
conditions. In order to generate pure inorganic nanostructures, the polymer template was removed by UV etching using a UV light source with a wavelength of $254 \mathrm{~nm}$ for 6 hours in air.

\subsection{Characterization}

The morphological studies were carried out with a Digital instruments 5000AFM (DI/Veeco, Santa Barbara, U.S.) operated in tapping mode. FTIR measurements were done using FTIR spectrometer (Varian, Scimitar series). UV-visible absorption measurements were carried out using a UV-vis-Near IR spectrophotometer (Varian, Cary 5000).

\section{Conclusions}

In this study, we have fabricated $\mathrm{SiO}_{2}-\mathrm{TiO}_{2}$ hybrid nanowires via self-assembly of block copolymer and sol-gel chemistry. Thin films of PS- $b$-PEO with silica/titania precursors incorporated in the PEO domains were obtained by one step spin-coating from the common solution. $\mathrm{SiO}_{2}-\mathrm{TiO}_{2}$ nanodot/nanowire structures can be obtained by utilizing solvents with different selectivity and by altering the relative volumetric ratio of sol-gel precursor to the polymer solution. We could reach a conclusion that ionic strength of the hybrid sol-gel and increasing relative volume of $\mathrm{SiO}_{2}-\mathrm{TiO}_{2}$ sol-gel precursor/BCP could induce structural change from nanodot to nanowire patterns. Subsequent UV treatment to remove the organic template resulted in the pure silica/titania nanostructures. Such mixed oxide nanostructures exhibited enhanced photocatalytic activity towards the photodecomposition of a selected organic dye. The methodology suggested by this work may open up a facile way to fabricate mixed oxide inorganic nanostructures.

\section{Acknowledgements}

This work was supported by National Research Foundation (NRF) of Korea Grant funded by the Korean Government (Nos. 20100001480; 20100016039; KRF-2007-313-D00363) and by the Converging ResearchCenter Program through the Ministry of Education, Science and Technology (2010K000990).

\section{References}

1. Linsebigler, A.L.; Guangquan, L.; John, T.Y. Photocatalysis on $\mathrm{TiO}_{2}$ surfaces: Principles, mechanisms, and selected results. Chem. Rev. 1995, 95, 735-758.

2. Brown, G.E.; Henrich, V.E.; Casey, W.H.; Clark, D.L.; Eggleston, C.; Femly, A.; Goodman, G.W.; Gretzel, M.; Macial, G.; McGarthy, M.I.; Nealson, K.H.; Sverjensky, D.A.; Toney, M.F.; Zachara, J.M. Metal oxide surfaces and their interactions with aqueous solutions and microbial organisms. Chem. Rev. 1999, 99, 77-174.

3. Bilmes, S.A.; Mandelbaum, P.; Alvarez, F.; Victoria, N.M. Surface and electronic structure of titanium dioxide photocatalysts. J. Phys. Chem. B 2000, 104, 9851-9858.

4. Hoffmann, M.R.; Martin, S.T.; Choi, W.; Bahnemann, D.W. Environmental applications of semiconductor photocatalysis. Chem. Rev. 1995, 95, 69-96. 
5. Huogen, Y.; Jiaguo, Y.; Bei, C.; Shengwei, L. Novel preparation and photocatalytic activity of one-dimensional $\mathrm{TiO}_{2}$ hollow structures. Nanotechnology 2007, 18, 065604.

6. Xiwang, Z.; Jia, H.P.; Alan, J.D.; Weijiong, F.; Darren, D.S.; James, O.L. Combination of one-dimensional $\mathrm{TiO}_{2}$ nanowire photocatalytic oxidation with microfiltration for water treatment. Water Res. 2009, 43, 1179-1186.

7. Mingxia, X.; Qinglin, Z.; Hongxing, L.; Guozhang, D.; Hongchun, Y.; Taihong, W.; Bingsuo, Z.; Yanguo, $\mathrm{W}$. The large-scale synthesis of one-dimensional $\mathrm{TiO}_{2}$ nanostructures using palladium as catalyst at low temperature. Nanotechnology 2009, 20, 055605.

8. Shimizu, K.; Murayama, H.; Nagai, A.; Shimada, A.; Hatamachi, T.; Kodama, T.; Kitayama, Y. Degradation of hydrophobic organic pollutants by titania pillared fluorine mica as a substrate specific photocatalyst. Appl. Catal. B Environ. 2005, 55, 141-148.

9. Guillard, C.; Disdier, J.; Monnet, C.; Dussaud, J.; Malato, S.; Blanco, J.; Maldonado, M.I.; Herrmann, J.M. Solar efficiency of a new deposited titaniaphotocatalyst: Cholorophenol, pesticide and dye removal applications. Appl. Catal. B Environ. 2003, 46, 319-332.

10. Rao, K.V.S.; Subrahmanyam, M.; Boule, P. Immobilized $\mathrm{TiO}_{2}$ photocatalyst during long-term use: Decrease of its activity. Appl. Catal. B Environ. 2003, 49, 239-249.

11. Zelenak, V.; Hornebecq, V.; Mornet, S.; Schaf, O.; Llewellyn, P. Mesoporous silica modified with titania: Structure and thermal stability. Chem. Mater. 2006, 18, 3184-3191.

12. Zhang, X.; Zhang, F.; Chan, K.Y. Synthesis of titania-silica mixed oxide mesoporous materials, characterization and photocatalytic properties. Appl. Catal. A Gen. 2005, 284, 193-198.

13. Cheng, Y.; Wang, K.; Lou, L. Photodegradtion of dye pollutants on silica gel supported $\mathrm{TiO}_{2}$ particles under visible light irradiation. J. Photochem. Photobiol. A Chem. 2004, 163, 281-287.

14. Hirano, M.; Ota, K. Direct formation and photocatalytic performance of anatase $\left(\mathrm{TiO}_{2}\right) /$ silica $\left(\mathrm{SiO}_{2}\right)$ composite nanoparticles. J. Am. Ceram. Soc. 2004, 87, 1567-1570.

15. Ginger, D.S.; Zhang, H.; Mirkin, C.A. The evolution of dip-pen nanolithography. Angew. Chem. Int. Ed. 2004, 43, 30-45.

16. Park, H.; Lim, A.K.L.; Alivisatos, A.P.; Park, J.; McEuen, P.L. Fabrication of metallic electrodes with nanometer separation by electromigration. Appl. Phys. Lett. 1999, 75, 301-303.

17. Xu, L.; Vemula, S.C.; Jain, M.; Nam, S.K.; Donnelly, V.M.; Economou, D.J.; Ruchhoeft, P. Nanopantography: A new method for massively parallel nanopatterning over large areas. Nano Lett. 2005, 5, 2563-2568.

18. Boncheva, M.; Whitesides, G.M. Theme article-making things by self-assembly. MRS Bull. 2005, 30, 736-742.

19. Bates, F.S.; Fredrickson, G.H. Block copolymer thermodynamics: Theory and experiment. Annu. Rev. Phys. Chem. 1990, 41, 525-557.

20. Fasolka, M.J.; Mayes, A.M. Block copolymer thin films: Physics and applications. Annu. Rev. Mater. Res. 2001, 31, 323-355.

21. Hamley, W. The Physics of Block Copolymer; Oxford University Press: New York, NY, USA, 1999; pp. 58-85.

22. Hashimoto, T.; Shilbayama, M.; Fujimura, M.; Kawai, H. Block Copolymers, Science and Technology; Harwood Academic: London, UK, 1993; pp. 63-98. 
23. Brinker, C.J.; Lu, Y.; Sellinger, A.; Fan, H. Evaporation-induced self-assembly: Nanostructures made easy. Adv. Mater. 1999, 11, 579-585.

24. Yu, K.; Hurd, A.J.; Eisenberg, A.; Brinker, J. Synthesis of silica/polystyrene-block-poly(ethylene oxide) films with regular and reverse mesostructures of large characteristic length scales by solvent evaporation-induced self-assembly. Langmuir 2001, 17, 7961-7965.

25. Förster, S.; Antonietti, M. Amphiphilic block copolymers in structure-controlled nanomaterials hybrids. Adv. Mater. 1998, 10, 195-217.

26. Finnefrock, A.C.; Ulrich, R.; Gruner, S.M.; Wiesner, U. Metal oxide containing mesoporous silica with bicontinuous "Plumber's Nightmare" morphology from a block copolymer hybrid mesophase. Angew. Chem. Int. Ed. 2001, 40, 1207-1211.

27. Simon, P.F.W.; Ulrich, R.; Spiess, H.W.; Wiesner, U. Block copolymer-ceramic hybrid materials from organically modified ceramic precursors. Chem. Mater. 2001, 13, 3464-3486.

28. Adachi, M.; Okumura, A.; Sivaniah, E.; Hashimoto, T. Incorporation of metal nanoparticles into a double gyroid network texture. Macromolecules 2006, 39, 7352-7357.

29. Lo, K.H.; Tseng, W.H.; Ho, R.M. In-situ formation of CdS nanoarrays by pore-filling nanoporous templates from degradable block copolymers. Macromolecules 2007, 40, 2621-2624.

30. Spontak, R.J.; Alexandridis, P. Advances in self-ordering macromolecules and nanostructure design. Curr. Opin. Colloid Interface Sci. 1999, 4, 140-146.

31. Li, X.; Peng, J.; Kang, J.H.; Choy, J.H.; Steinhart, M.; Knoll, W.; Kim, D.H. One step route to the fabrication of arrays of $\mathrm{TiO}_{2}$ nanobowls via a complementary block copolymer templating and sol-gel process. Soft Matter 2008, 4, 515-521.

32. Kim, D.H.; Kim, S.H.; Lavery, K.; Russell, T.P. Inorganic nanodots from thin films of block copolymers. Nano Lett. 2004, 4, 1841-1844.

33. Kim, J.M.; Stucky, G.D. Synthesis of highly ordered mesoporous silica materials using sodium silicate and amphiphilic block copolymers. Chem. Commun. 2000, doi: 10.1039/b002362k.

34. Kim, D.H.; Sun, Z.; Russell, T.P.; Knoll, W.; Gutmann, J.S. Organic-inorganic nanohybridization by block copolymer thin films. Adv. Funct. Mater. 2000, 15, 1160-1164.

35. Jang, Y.H.; Kochuveedu, S.T.; Cha, M.A.; Jang, Y.J.; Lee, J.Y.; Lee, J.; Lee, J.Y.; Kim, J.Y; Ryu, D.Y; Kim, D.H. Synthesis and photocatalytic properties of hierarchical metal nanoparticles/ZnO thin films hetero nanostructures assisted by diblock copolymer inverse micellar nanotemplates. J. Colloid Interface Sci. 2010, 345, 125-130.

36. Glass, R.; Moller, M.; Spatz, J.P. Block copolymer micelle nanolithography. Nanotechnology 2003, 14, 1153-1160.

37. Anderson, C.; Bard, A.J. Improved photocatalytic activity and characterization of mixed $\mathrm{TiO}_{2} / \mathrm{SiO}_{2}$ and $\mathrm{TiO}_{2} / \mathrm{Al}_{2} \mathrm{O}_{3}$ materials. J. Phys. Chem. B 1997, 101, 2611-2616.

38. Lee, B.Y.; Kim, S.W.; Lee S.C.; Lee, H.H.; Choung, S.J. Photocatalytic decomposition of gaseous formaldehyde using $\mathrm{TiO}_{2}, \mathrm{SiO}_{2}-\mathrm{TiO}_{2}$ and $\mathrm{Pt}-\mathrm{TiO}_{2}$. Int. J. Photoenergy 2003, 5, 21-25.

39. Chen, Y.; Wang, K.; Lou, L. Photodegradation of dye pollutants on silica gel supported $\mathrm{TiO}_{2}$ particles under visible light irradiation. J. Photochem. photobiol. A Chem. 2004, 163, 281-287. 


\section{Appendix}

Figure S1. Height contrast AFM images of the surfaces of (a) neat PS- $b$-PEO film; (b) $\mathrm{PS}-b-\mathrm{PEO} / \mathrm{SiO}_{2}-\mathrm{TiO}_{2}$ film containing 10 vol\% inorganic precursors; (c) identical film in (b) after removing the $\mathrm{BCP}$ templates; (d) $\mathrm{PS}-b-\mathrm{PEO} / \mathrm{SiO}_{2}-\mathrm{TiO}_{2}$ film containing 20 vol\% inorganic precursors; (e) identical film in (d) after removing the BCP templates. The hybrid films were prepared from spin coating dioxane solutions. Ti/Si mass ratio is 0.5 .
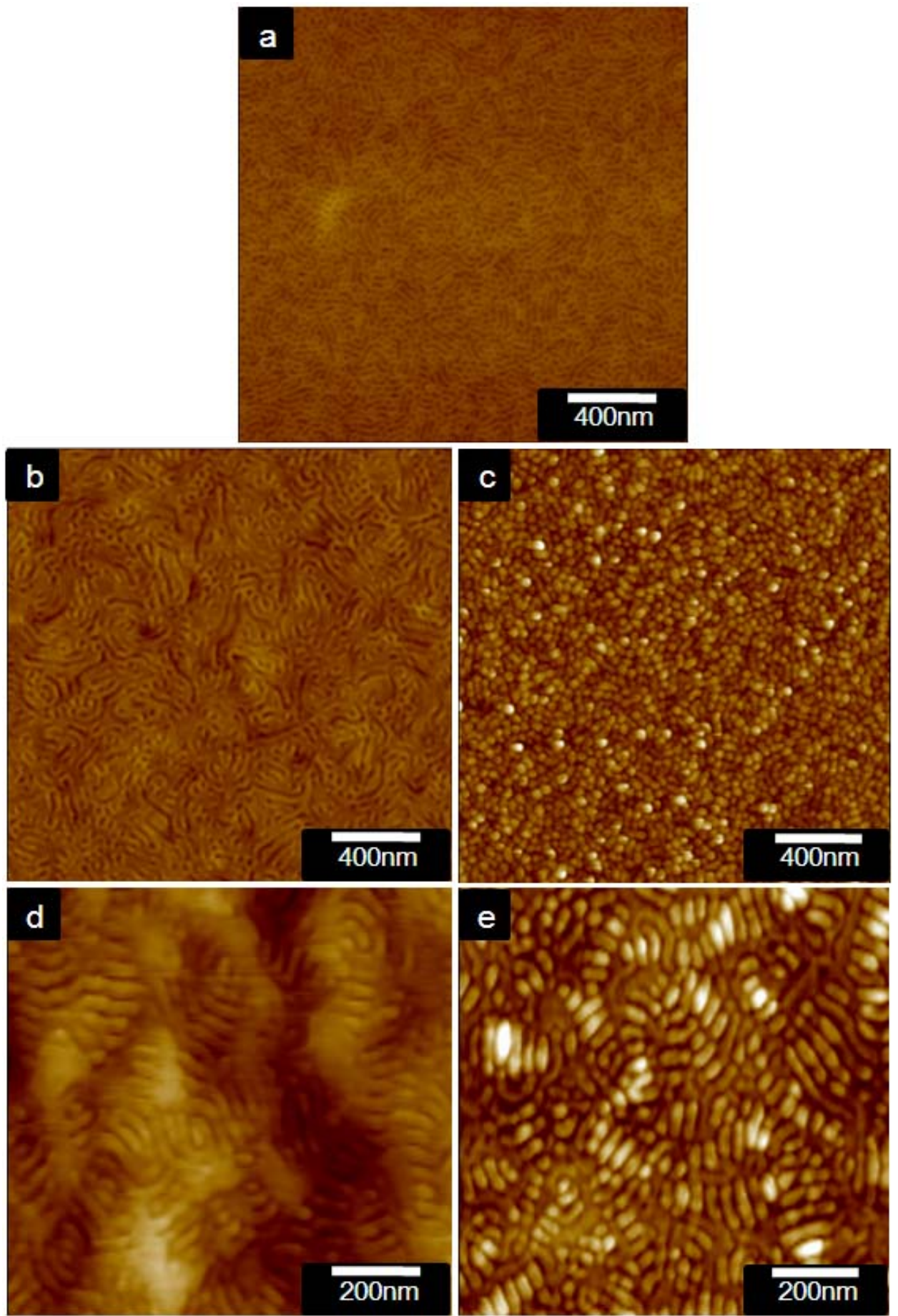
Figure S2. Height contrast AFM images of the surfaces of PS- $b-\mathrm{PEO} / \mathrm{SiO}_{2}-\mathrm{TiO}_{2}$ film containing (a) $10 \mathrm{vol} \%$ inorganic precursors; (b) 15 vol\% inorganic precursors; (c) the identical film in (b) after removing the BCP templates; (d) $\mathrm{PS}-b-\mathrm{PEO} / \mathrm{SiO}_{2}-\mathrm{TiO}_{2}$ film containing $20 \mathrm{vol} \%$ inorganic precursors; (e) identical film in (d) after removing the BCP templates. The hybrid films were prepared from spin coating dioxane solutions. Ti/Si mass ratio is 1.0 .

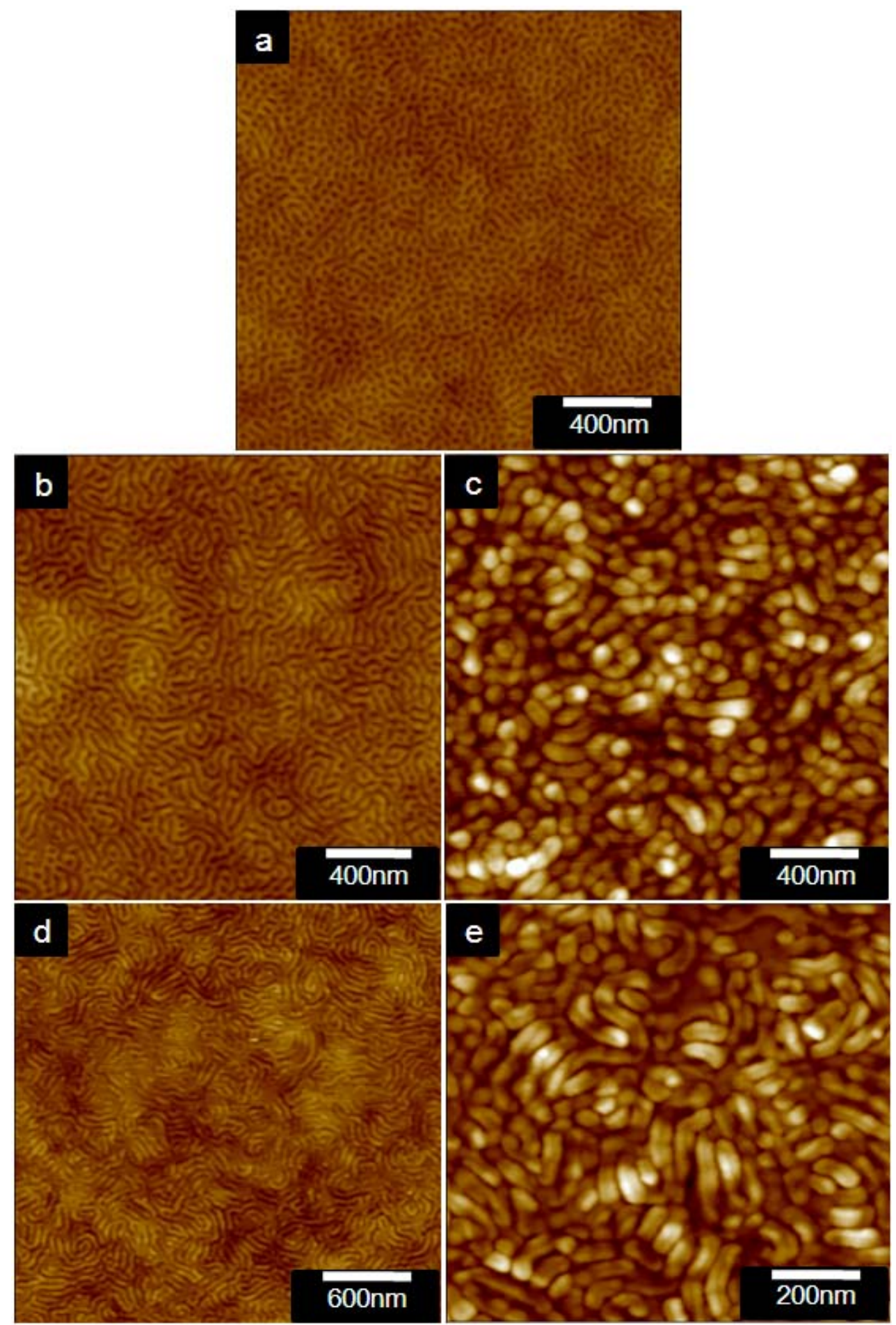


Figure S3. Height contrast AFM images of the surfaces of (a) PS- $b-\mathrm{PEO} / \mathrm{SiO}_{2}-\mathrm{TiO}_{2}$ film containing $10 \mathrm{vol} \%$ inorganic precursors; (b) identical film in (a) after removing the BCP templates; (c) $\mathrm{PS}-b-\mathrm{PEO} / \mathrm{SiO}_{2}-\mathrm{TiO}_{2}$ film containing $20 \mathrm{vol} \%$ inorganic precursors; (d) identical film in (c) after removing the BCP templates. The hybrid films were prepared from spin coating dioxane solutions. Ti/Si mass ratio is 1.5 .

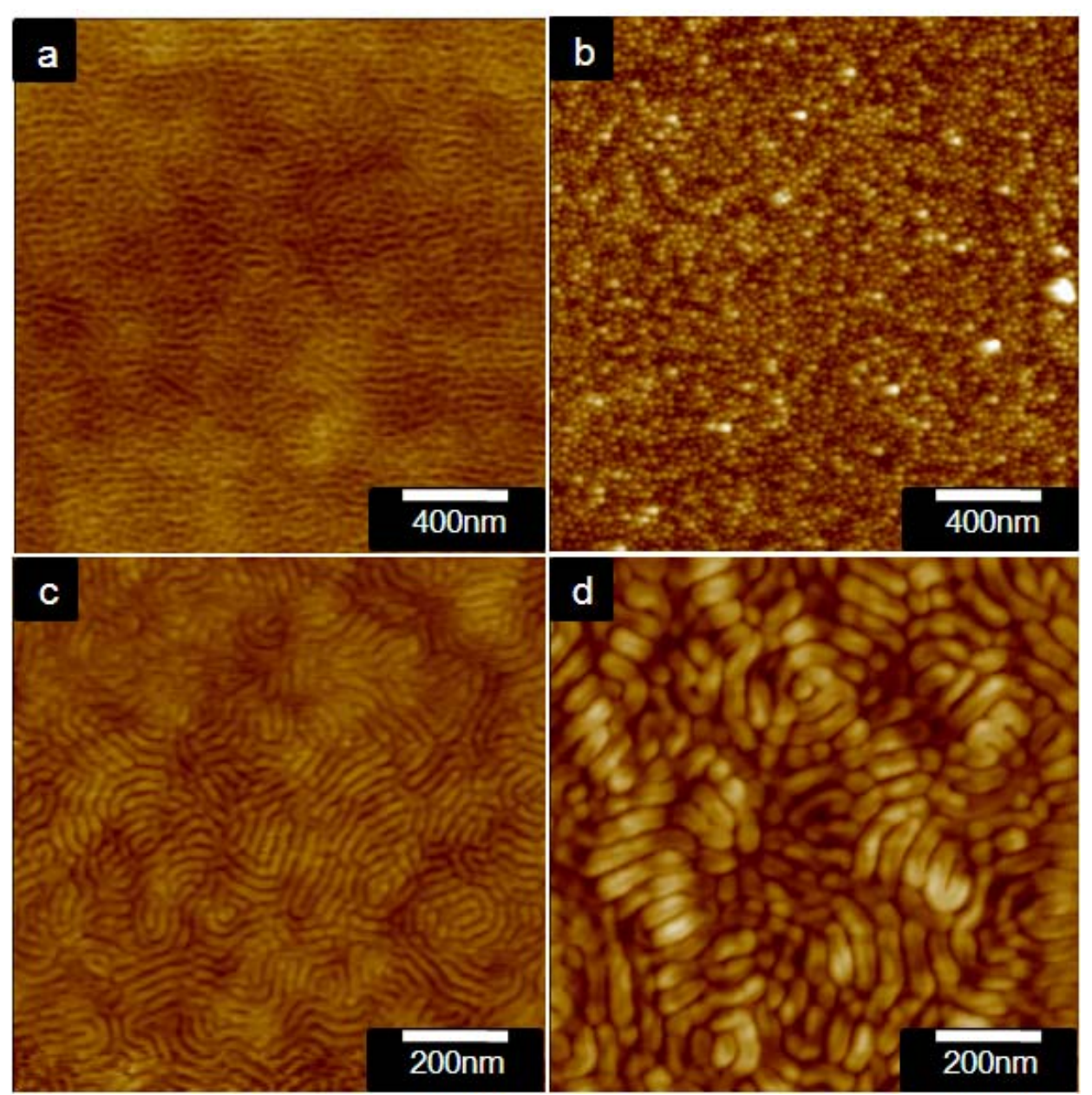

(C) 2010 by the authors; licensee MDPI, Basel, Switzerland. This article is an open access article distributed under the terms and conditions of the Creative Commons Attribution license (http://creativecommons.org/licenses/by/3.0/). 